\title{
Transcriptome Analysis of the Barley-Fusarium graminearum Interaction
}

\author{
Jayanand Boddu, Seungho Cho, Warren M. Kruger, and Gary J. Muehlbauer \\ Department of Agronomy and Plant Genetics, University of Minnesota, St. Paul, MN 55108 U.S.A. \\ Submitted 1 August 2005. Accepted 12 December 2005.
}

Fusarium head blight (FHB) of barley (Hordeum vulgare L.) is caused by Fusarium graminearum. FHB causes yield losses and reduction in grain quality primarily due to the accumulation of trichothecene mycotoxins such as deoxynivalenol (DON). To develop an understanding of the barley$F$. graminearum interaction, we examined the relationship among the infection process, DON concentration, and host transcript accumulation for 22,439 genes in spikes from the susceptible cv. Morex from 0 to $144 \mathrm{~h}$ after $F$. graminearum and water control inoculation. We detected 467 differentially accumulating barley gene transcripts in the $F$. graminearum-treated plants compared with the water controltreated plants. Functional annotation of the transcripts revealed a variety of infection-induced host genes encoding defense response proteins, oxidative burst-associated enzymes, and phenylpropanoid pathway enzymes. Of particular interest was the induction of transcripts encoding potential trichothecene catabolic enzymes and transporters, and the induction of the tryptophan biosynthetic and catabolic pathway enzymes. Our results define three stages of $F$. graminearum infection. An early stage, between 0 and $48 \mathrm{~h}$ after inoculation (hai), exhibited limited fungal development, low DON accumulation, and little change in the transcript accumulation status. An intermediate stage, between 48 and 96 hai, showed increased fungal development and active infection, higher DON accumulation, and increased transcript accumulation. A majority of the host gene transcripts were detected by 72 hai, suggesting that this is an important timepoint for the barley- $F$. graminearum interaction. A late stage also identified between 96 and 144 hai, exhibiting development of hyphal mats, high DON accumulation, and a reduction in the number of transcripts observed. Our study provides a baseline and hypothesisgenerating dataset in barley during $F$. graminearum infection and in other grasses during pathogen infection.

Additional keywords: RNA profiling.

Fusarium head blight (FHB) is a serious disease of barley (Hordeum vulgare L.) and wheat grown in humid and semihumid climates (McMullen et al. 1997; Parry et al. 1995). Fusarium graminearum Schwabe (teleomorph Gibberella zeae (Schwein) Petch) is the most common pathogen, although other Fusarium spp. are also pathogenic. Disease symptoms

Corresponding author: Gary J. Muehlbauer; Telephone: 612-625-6228; Fax: 612-625-1268; E-mail: mueh1003@umn.edu

* The $\boldsymbol{e}$-Xtra logo stands for "electronic extra" and indicates the HTML abstract available on-line contains supplemental tables and figures not included in the print edition. develop in spike tissue and are marked by premature necrosis. In addition to yield loss, the accumulation of trichothecene mycotoxins such as deoxynivalenol (DON) results in loss of quality for the remaining grain. These mycotoxins have been implicated in pathogenesis, phytotoxicity, and the induction of apoptosis in eukaryotic cell cultures (Kang and Buchenauer 1999; Miller and Ewen 1997; Shifrin and Anderson 1999). Partial control of FHB on barley is through a combination of management practices and partially resistant varieties.

The development of FHB on barley is a complex process. Infection is initiated after the spike has emerged from the flag leaf sheath in the late-milk to soft-dough stages of seed development (Bushnell et al. 2003). F. graminearum colonizes brush hairs (ovary epithelial hairs) at the extruded seed tip, followed by invasion into the developing caryopsis (Skadsen and Hohn 2004). Disease symptoms do not spread in the spike, even in susceptible cultivars, indicating that barley exhibits a natural level of FHB resistance (Bushnell et al. 2003). In contrast, wheat flowers emerge from the flag leaf sheath before anthesis and are susceptible to FHB during anthesis, and disease symptoms spread through the spike. Some resistant wheat genotypes exhibit resistance to spread of the disease in the spike, which is referred to as type II resistance (Mesterhazy 1995). Because barley exhibits natural type II resistance, understanding the infection pathways and host response in barley could provide insight into the mechanisms of type II resistance.

Although something is known about the infection strategies and pathways of $F$. graminearum on barley, the interaction of the pathogen with wheat may be instructive. In wheat, the fungus has been shown to penetrate through stomatal openings, grow between crevices in the floral bracts (lemma and palea), or penetrate directly through the adaxial surface of floral bracts (Bushnell et al. 2003). The fungus exhibits subcuticular growth, develops infection hypha, colonizes ovary and floral bract tissue, and sporulates within $72 \mathrm{~h}$ after inoculation (hai) (Bushnell et al. 2003; Pritsch et al. 2000). In addition, F graminearum displays traits of a biotroph during the initial 48 to 72 hai, then switches to a necrotrophic phase at approximately 72 hai (Bushnell et al. 2003; Kang and Buchenauer 1999). As wheat spikes become infected by $F$. culmorum (a closely related Fusarium sp. that also causes FHB), cell wall components are reduced, indicating that F. culmorum produces cell-wall-degrading enzymes to assist infection (Kang and Buchenauer 2000a,b; 2002). Furthermore, $F$. graminearum and F. culmorum produce trichothecene mycotoxins that are known to inhibit protein synthesis and increase virulence (Desjardins and Hohn 1997; Kang and Buchenauer 1999; Proctor et al. 1995).

Host response to $F$. graminearum infection has been studied in wheat. Wheat responds to $F$. graminearum and $F$. culmorum infection by inducing various defenses. Transcripts of several classes of biotic stress-related genes accumulate locally and 
systemically in both partially resistant and susceptible cultivars (Kang and Buchenauer 2002; Li et al. 2001; Pritsch et al. 2000, 2001). Moreover, the lignin content in cell walls of two resistant cultivars increased dramatically during infection by $F$. culmorum compared with that of uninoculated plants (Kang and Buchenauer 2000c). These data suggest that the host response to Fusarium spp. infection on wheat is complex and combines an assortment of defense responses, including activation of defense response genes and lignin deposition. To date, an examination of the molecular genetic host response in barley to $F$. graminearum infection has not been conducted.

Genetic resistance to FHB in barley and wheat is partial and quantitatively controlled by many loci. Quantitative trait loci (QTL) for FHB resistance have been identified on each of the seven barley chromosomes (Dahleen et al. 2003; de la Peña et al. 1999; Ma et al. 2000; Mesfin et al. 2003; Zhu et al. 1999) and mapping of FHB resistance in wheat also has revealed multiple QTL that confer partial resistance (Anderson et al. 2001; Bai et al. 1999; Buerstmayr et al. 2002; Otto et al. 2002; Waldron et al. 1999; Zhou et al. 2002). Loci that control resistance $(\mathrm{R})$ in a gene-for-gene manner have not been detected in the small grain-Fusarium spp. interactions, and the standard genetics approaches to studying these interactions are not available. RNA profiling offers an approach to establish a baseline understanding and hypothesis-generating dataset of the barley-Fusarium spp. interaction.

RNA profiling enables the large-scale examination of transcript accumulation as a function of temporal and spatial events. To examine transcript accumulation in barley under a variety of conditions and developmental stages, a Barley 1 Affymetrix GeneChip probe array representing 22,439 genes was developed (Close et al. 2004). Caldo and associates (2004) used the Barley1 GeneChip to examine transcript accumulation in barley infected with Blumeria graminis f. sp. hordei during compatible and incompatible interactions. These authors identified transcripts that accumulated differentially in the incompatible and compatible interactions and showed a link between basal defense responses and gene-for-gene specific resistance, demonstrating the power of the Barley1 GeneChip to study barley-pathogen interactions.

To gain an understanding of the relationships among fungal infection, trichothecene accumulation, and transcript abundance in barley during $F$. graminearum infection, we conducted a microscopic analysis of the infection process, determined the levels of DON concentration, and used the Barley1 Affymetrix GeneChip probe array to determine transcript accumulation. Our data show a clear relationship among disease development, DON concentration, and host gene transcript accumulation. We delineated three stages of the barley $-F$. graminearum interaction: (i) an early stage from 0 to 48 hai, (ii) an intermediate stage from 48 to 96 hai, and (iii) a late stage from 96 to 144 hai. At 72 hai, we observed the active infection of barley tissues, DON accumulation, and the altered expression of the majority of the host genes, suggesting that this timepoint is important for the barley- $F$. graminearum interaction. In addition, functional annotation of the GeneChip data shows that a variety of host defense responses are induced during infection. The dataset generated in this study provides a baseline for future comparative analysis of barley and wheat infected with F. graminearum and other grass species-pathogen interactions.

\section{RESULTS}

Fungal infection and disease progression.

We examined the general disease progression on sprayinoculated spikes of the FHB susceptible barley cv. Morex from 0 to 240 hai (data not shown). Symptoms were just barely apparent as visible discoloration on the bract tissues at 48 hai, and were clearly visible at 72 hai. Furthermore, when infected florets were dissected, we noticed that symptoms generally were more acute on the adaxial surface of the floral bracts that surround the caryopsis. We scored the level of disease symptoms at 240 hai and found that, on average, approximately $45 \%$ of the florets on a spike were diseased.

We examined lemma tissue of spray-inoculated barley spikes to follow the progression of $F$. graminearum infection at $24,48,72,96$, and 144 hai by light and scanning electron microscopy (Fig. 1). At 24 hai, we observed germinated conidiospores and limited hyphal growth on the inoculated, abaxial surface, but none on the adaxial surface of the lemma (Fig. 1A). We did not see disease symptoms at this time, indicating that there was limited infection during the initial 24 hai. We observed the first symptom of disease, which was visible as brown discoloration, in the lemma at 48 hai. At 48 hai, hyphal growth was predominantly on the adaxial surface of the lemma. This suggests that the initial onset of "true" infection of barley florets by $F$. graminearum is between 24 and 48 hai. We observed a steady and substantial increase in the amount of hyphal growth on the adaxial surface of the lemma as disease progressed from 72 to 144 hai (Fig. 1C, E, and F).

As early as 48 hai and throughout the infection process, we observed multiple $F$. graminearum hyphae or secondary hyphal structures with differences in hyphal thickness, length, or both (Fig. 1). We observed a number of short hyphae and infection-like hyphae (Fig. 1B and G). Subcuticular growth was distinctly visible at 72 to 96 hai (Fig. $1 \mathrm{G}$ and H). Coralloid bulges at the end of secondary peg-like structures were observed at putative infection penetration sites (Fig. 1D). Also, between 72 and 96 hai, we observed hyphae above or very close to stomates, which often were observed to grow through stomatal pores (Fig. 1E and $\mathrm{H}$ ). In addition to gross differences in hyphal structure, we also noticed septae-like structures within hyphae (Fig. 1A and D).

\section{DON accumulation.}

We determined the timing and concentration of DON accumulation in both $F$. graminearum- and mock-inoculated spikes at 24, 48, 72, 96, and 144 hai (Fig. 2). We did not find measurable levels of DON in any of the mock-inoculated samples. We also did not detect DON in the $F$. graminearum-infected samples at 24 hai. Our first measurable level of DON was at 48 hai, but this was at a very low level (average of $0.23 \mathrm{ppm} / \mathrm{g}$ of tissue). DON concentrations showed substantial variation, but the average level increased to $12.8 \mathrm{ppm} / \mathrm{g}$ of tissue by 72 hai (an over 50-fold increase from the level at 48 hai), and increased to $15.6 \mathrm{ppm} / \mathrm{g}$ tissue at 96 hai and $55.7 \mathrm{ppm} / \mathrm{g}$ tissue at 144 hai (an over 3.5-fold increase from the level at 96 hai).

\section{Barley transcript accumulation \\ in response to $F$. graminearum infection.}

We used the Barley1 GeneChip to measure and compare the transcript accumulation of 22,439 barley genes between $F$. graminearum- and mock (water)-inoculated barley spikes at 24, 48, 72, 96, and 144 hai. Four independent replications of the experiment and a fifth replication at 24 and 72 hai were conducted (see Materials and Methods). All GeneChip data were analyzed in the Genedata Expressionist Pro software (version 1.0). Genedata Expressionist software has two major tools, namely the Refiner for condensation and normalization and the Analyst for analysis. GeneChip data were condensed and normalized by robust multichip analysis (RMA) (Irizarry et al. 2003) in the Refiner tool. To obtain better comparable distribution of signal intensity across all chips, we conducted additional signal scaling to a target intensity of 500. Additional 

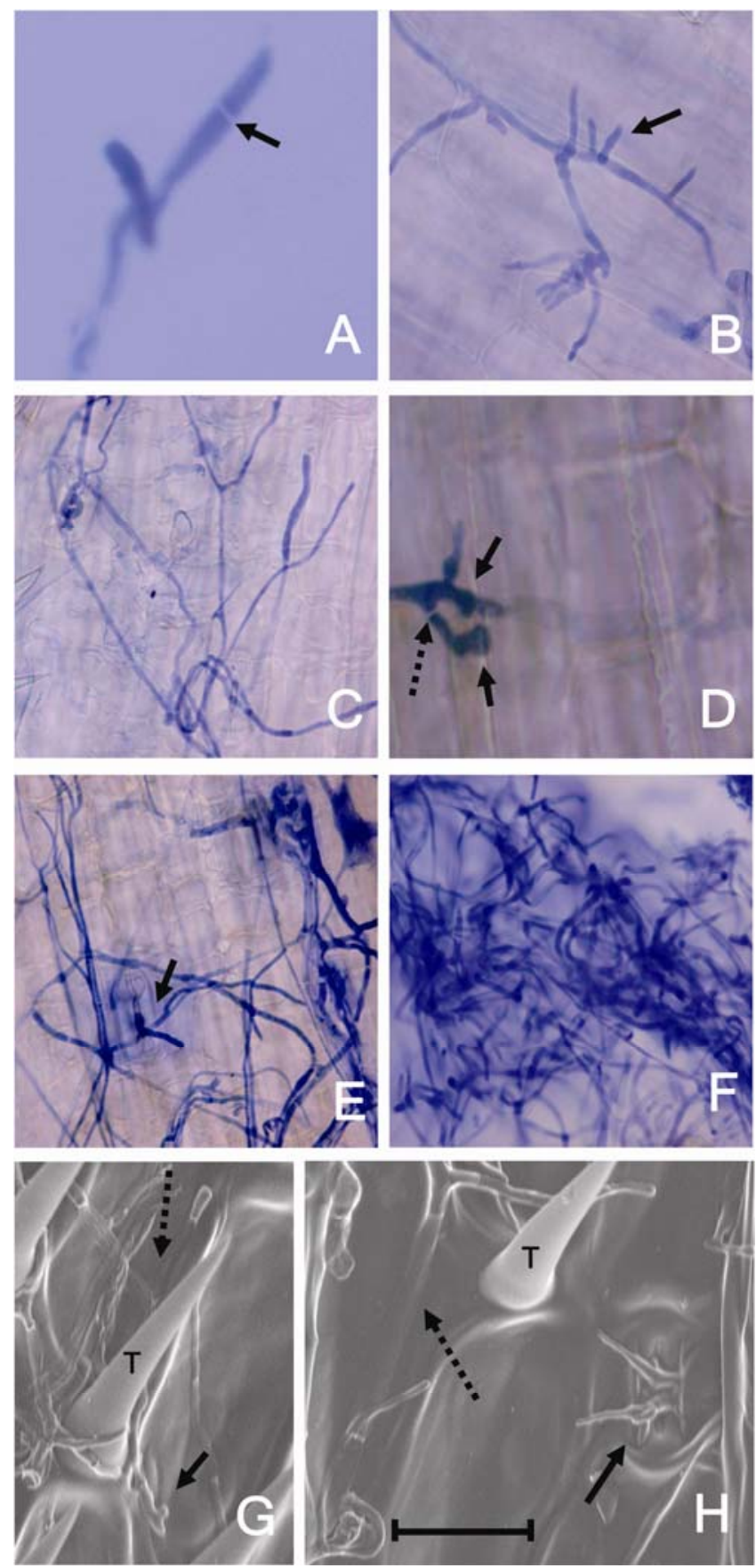

Fig. 1. Light and scanning electron micrographs of Fusarium graminearum growth on the lemma of barley florets. A, Germination of a fungal spore at $24 \mathrm{~h}$ after inoculation (hai). Small arrow shows septa. B, Secondary structure formation and hyphal growth at 48 hai. Small arrow indicates short hyphae with small bulge in the subtending hyphal wall. $\mathbf{C}, \mathrm{Hy}$ phal growth at 72 hai. D, Putative penetration site proceeded by coralloid bulge at the end of the peg-like structure at 96 hai. Small arrows show formation of coralloid bulges. Dotted arrow shows the septa. E, Increase in hyphal growth at 96 hai. Small arrow shows the hyphal growth through a stomatal pore. F, Increase in the density of hyphal growth at 144 hai. G, Scanning electron micrograph showing subcuticular growth and infection hyphae at 96 hai. Small arrow shows infection hypha and dotted arrow shows subcuticular growth. H, Scanning electron micrograph showing fungal hyphae interacting with stomata and subcuticular growth at 96 hai. Small arrow shows the stomatal interaction and the dotted arrow shows the subcuticular growth. Scale bar is $15 \mu \mathrm{m}$ in A, $50 \mu \mathrm{m}$ in B, $60 \mu \mathrm{m}$ in C, 30 $\mu \mathrm{m}$ in $\mathrm{D}, 60 \mu \mathrm{m}$ in $\mathrm{E}, 60 \mu \mathrm{m}$ in $\mathrm{F}, 30 \mu \mathrm{m}$ in $\mathrm{G}$, and $30 \mu \mathrm{m}$ in $\mathrm{H}$; $\mathrm{T}=$ trichome. signal scaling after the RMA condensation and normalization did not affect the shape of the expression profiles (data not shown). Correlation coefficients between replications ranged from 0.89 to 0.99 . We conducted parametric two-way analysis of variance (ANOVA; $P$ value $\leq 0.001$ ) and false discovery rate (FDR) tests at the 5\% level to identify transcripts exhibiting treatment differences and identified 1,048 probe sets. In this case, we assumed a single probe set is equivalent to a single transcript. To validate the signal of the 1,048 transcripts that exhibited differential accumulation between treatments, we conducted a presence or absence test (detection $P$ value $=0.04$ ) using MAS 5.0 in the Analyst tool. We designated a transcript as present when it showed a significant expression value in at least two replicates and detected a total of 946 transcripts. From these 946 transcripts, we used two general approaches to identify genes that exhibited differential transcript accumulation between plants inoculated with $F$. graminearum or water (mock). The first was to identify transcripts that were present in one treatment and not in the other. These transcripts were considered qualitative in nature. Probe sets that were detected in two or more replications in one of the treatments and absent in all replications in the other treatment were identified. The second was to identify transcripts that were present in both treatments but exhibited a statistically significant difference in transcript accumulation between the two treatments. These transcripts were considered quantitative in nature. Quantitative transcripts were those that exhibited a twofold and greater difference between treatments. These strict criteria for detecting transcripts were chosen to ensure that the detected transcripts were robust.

We identified a total of 497 probe sets that detected transcripts that were expressed differentially between $F$. graminearum- and mock (water)-inoculated barley spikes at one or more timepoints between 24 and 144 hai. The transcript accumulation always was greater in the $F$. graminearum-treated plants, except for three genes that were downregulated (Contig3553_at at $72 \mathrm{~h}$ and Contig14066_at and Contig21640_at at 144 h). The differentially accumulating transcripts were placed into two subgroups depending on whether they were identified as qualitative or quantitative. We designated a group of 242 transcripts identified by present versus absent as "qualitatively" expressed genes. In all, 255 transcripts were identified as significantly induced in $F$. graminearum- versus mock-inoculated barley spikes and were designated "quantitatively" expressed.

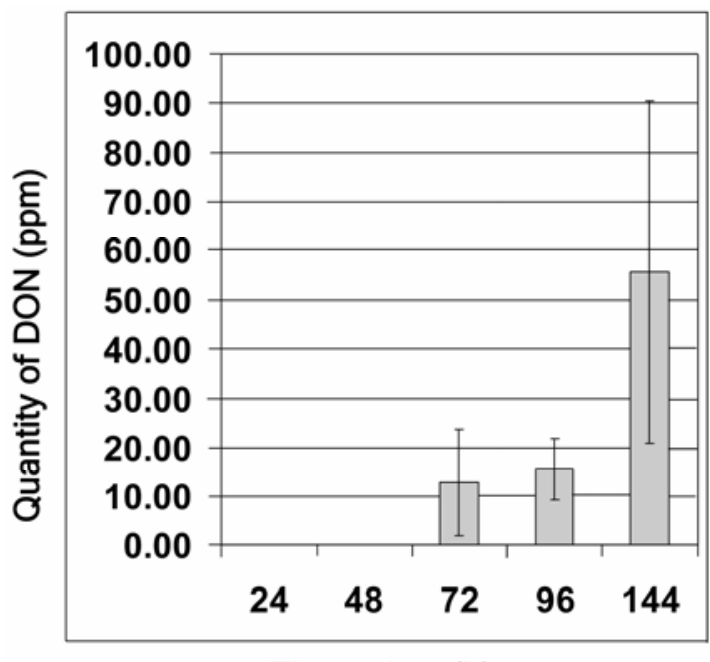

Timepoints (h)

Fig. 2. Deoxynivalenol (DON) concentrations at 24, 48, 72, 96, and $144 \mathrm{~h}$ after inoculation (hai). Mean values were obtained from five replications at 24 and 72 hai and four replications at 48, 96, and 144 hai. 
The Barley1 GeneChip was designed from expressed sequence tag (EST) collections from a variety of cDNA libraries. One of the cDNA libraries used for sequencing barley ESTs was derived from barley spikes infected with $F$. graminearum (Close et al. 2004). Thus, we sought to identify probe sets derived from $F$. graminearum sequences that inadvertently may have been placed on the Barley1 GeneChip. We conducted BLASTN searches of all genes that were identified in our experiment as upregulated in the $F$. graminearum treated plants against the $F$. graminearum genome sequence. We considered a probe set sequence as fungal when the $e$ value was $\leq 10^{-84}$ and the percent identity was $\geq 95 \%$ to a $F$. graminearum genome sequence. We detected 30 probe sets of fungal origin exhibiting a qualitative nature for transcript accumulation. All of the 30 probe sets were derived from the EST collection from the library prepared from barley infected with $F$. graminearum. In all, 25 of the $F$. graminearum transcripts were detected by 72 hai, with 16 of these initially detected at 72 hai. Subtracting the $30 \mathrm{~F}$. graminearum transcripts from the 242 qualitatively expressed transcripts resulted in 212 barley transcripts exhibiting a qualitative accumulation pattern. As expected, no genes that were in the quantitative class were annotated as derived from $F$. graminearum.

Barley transcripts that exhibited differential accumulation between $F$. graminearum-infected and mock-inoculated plants showed distinct patterns across the timepoints. Transcripts that met the criteria for qualitative and quantitative accumulation were clustered separately according to common accumulation pattern (Fig. 3). For example, transcripts that exhibited a present call in the F. graminearum-infected plants and an absent call in the mock-inoculated plants at 24, 48, 72, 96, and 144 hai were clustered into qualitative group 1 (Q11). Transcripts that exhibited a statistically significant difference between $F$. graminearum-infected and mock-inoculated plants $(P \leq 0.001$; FDR 5\%) and greater than twofold change at the timepoints $24,48,72,96$, and 144 hai were clustered into quantitative group 1 (Qn1). The
11 and 13 clusters for the qualitative and quantitative transcripts, respectively, are shown in Figure 3. Some of the patterns showed discontinuous expression (Fig. 3; Q18, Q111, Qn9, Qn11, and Qn13) or were detected at only a single timepoint (Fig. 3; Q15, Q16, Q17, Qn6, Qn7, and Qn8). In these cases, the lack of detection at the intervening timepoint (discontinuous expression pattern) and prior or subsequent timepoints (single timepoint pattern) largely was due to expression values that were slightly below our set threshold levels.

Closer observation of the transcript accumulation clusters suggested that major changes in gene expression occurred between 48 and 72 hai. Our qualitative transcript accumulation cluster classification showed that the cluster Q13 (83 transcripts) was the largest group, and these transcripts were identified from 72 hai to 144 hai (Fig. 3). Similarly, when we observed the quantitative gene clusters, we identified 159 transcripts that satisfied the quantitative criteria at 72 hai exclusively or that showed initiation of significant expression at 72 hai (Fig. 3; Qn3, Qn7, Qn12, and Qn13). Our results showed that the overall transcript number and the number of transcripts first detected were greatest at 72 hai (Fig. 3).

\section{Functional classification.}

We conducted a broadbased classification of all the differentially expressed barley genes into six categories according to biological or molecular function. These gene categories were designated defense response, metabolic, regulatory, transport, miscellaneous, and unknown. Functional annotation of each probe set was based on those provided for the Barley1 GeneChip on HarvEST. Genes were categorized in functional classes based on an $e$ value of $<10^{-10}$. The defense response class of genes encoded proteins such as chitinase, $\beta$-1,3-glucanase, thaumatin-like proteins, glutathione- $S$-transferase, and oxalate oxidase. Genes encoding enzymes involved in metabolism-related functions included dehydrogenases, phenylpropanoid pathway
A

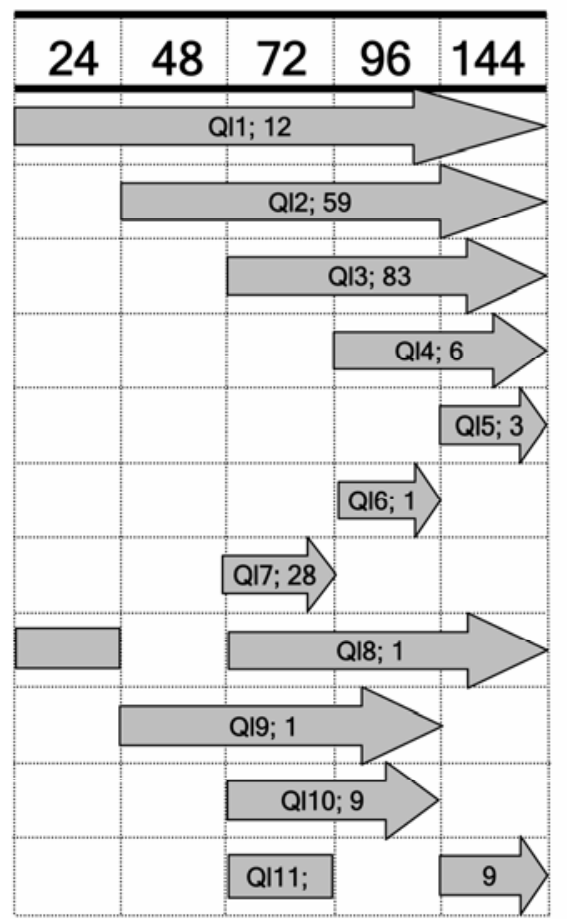

B

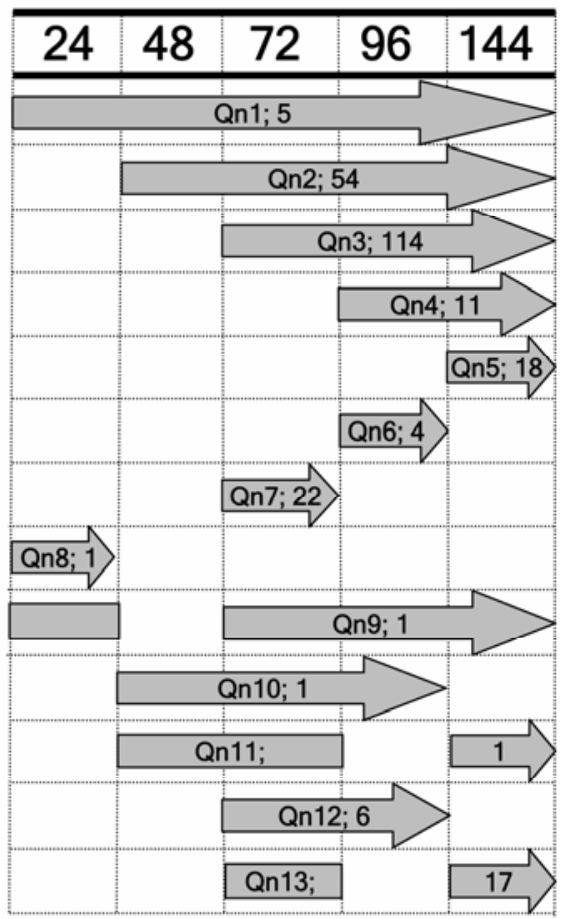

Fig. 3. Patterns of expression of qualitative and quantitatively expressing genes. A, Diagrammatic representation of the 11 patterns of qualitative transcript accumulation. The numbers of transcripts in each pattern are shown. B, Diagrammatic representation of the 13 patterns of quantitative transcript accumulation. The numbers of transcripts in each pattern are shown. The numbers 24, 48, 72, 96, and 144 refer to the number of hours after inoculation. 
enzymes, and cytochrome P450-like enzymes. Genes encoding DNA-binding proteins such as WRKY domain containing proteins were placed in the regulatory class. Genes annotated with a transporter function were placed in the transport class. All other annotated barley genes were placed in the miscellaneous class. Genes without annotations or annotations that exhibited $e$ values $>10^{-10}$ were placed in the unknown class.

We combined the qualitative and quantitative sets of 467 barley transcripts and tallied the total number of genes in each of the functional categories. We identified 146, 113, 82, 78, 24, and 24 genes encoding metabolic, unknown, defense response, miscellaneous, regulatory, and transporter functions, respectively.

We examined our transcript accumulation data for upregulation of specific metabolic pathways. Probe sets annotated to tryptophan metabolic and catabolic pathway genes were identified (Fig. 4). We detected transcript accumulation from each gene in the biosynthetic pathway from chorismate to tryptamine. Multiple probe sets annotated as indole 3-glycerolphosphate synthase $(n=3)$, tryptophan synthase- $\beta$ chain $(n=3)$, and tryptophan decarboxylase $(n=2)$ were found. Interestingly, all tryptophan biosynthetic genes showed transcript accumulation patterns that were quantitative in nature. However, multiple probe sets detecting tryptophan decarboxylase transcripts showed transcript accumulation patterns that were qualitative in nature. One probe set encoding shikimate kinase also was detected. Shikimate kinase is a member of the shikimate pathway, which supplies precursors to the tryptophan biosynthetic pathway.

\section{Validation of Barley1 GeneChip data.}

To validate the Barley1 GeneChip data, we conducted RNA gel blot analysis on five genes identified as exhibiting differential transcript accumulation (Fig. 5). These genes represent functions including defense response related (glucan-endo-1,3$\beta$-D-glucosidase, oxalate oxidase, glutathione- $S$-transferase), and metabolism (phosphoribosyl anthranilate transferase, catecol- $O$-methyltransferase). Our results show that each of the five genes exhibited increased transcript accumulation in plants infected with $F$. graminearum compared with the water controls, confirming the GeneChip data. In addition, the transcript accumulation data determined by the RNA gel blots showed a similar qualitative or quantitative nature and timing of upregulation as detected using the GeneChip. For example, the glucan-endo-1,3- $\beta$-D-glucosidase and phosphoribosyl anthranilate transferase transcripts were classified in the quantitative gene list, whereas the other three were classified as qualitatively expressing genes.

\section{DISCUSSION}

FHB is a serious disease of barley, and the accumulation of trichothecene mycotoxins during disease progression is a particularly important problem for end users of barley grain. Resistance to FHB in barley is partial, does not follow the genefor-gene model, and is inherited in a quantitative fashion (Dahleen et al. 2003; de la Peña et al. 1999; Ma et al. 2000; Mesfin et al. 2003; Zhu et al. 1999). Thus, we took an RNA profiling approach to examine the barley- $F$. graminearum interaction. We used the Barley1 GeneChip to identify transcript accumulation patterns in the susceptible barley cv. Morex challenged with $F$. graminearum and water. Our analysis allowed us to identify the general timing of host response and to assign functional annotations to the differentially accumulating transcripts. These data provide a baseline and hypothesis-generating dataset for transcript accumulation in barley during F. graminearum infection. Histological evaluation of disease development and quantitative analysis of DON accumulation supplemented the gene transcript information. These observations provide the first molecular glimpse at the complex interaction between barley and $F$. graminearum.

\section{F. graminearum infection of barley exhibits many of the hallmarks of infection of wheat.}

Barley and wheat are highly related members of the grass family; however, the FHB infection phenotypes on susceptible wheat and barley genotypes are different (G. J. Muehlbauer, unpublished results). In highly susceptible wheat, the infection spreads from floret to floret and the entire spike becomes diseased, whereas in type II resistant wheat genotypes (resistance characterized by limitation of symptom spread within the spike), infection is confined to the infected spikelets. In highly susceptible barley, infection does not spread and is largely restricted to the initially infected florets, closely resembling natural type II resistance in wheat.

Although the disease phenotypes differ between wheat and barley, our results show that many aspects of $F$. graminearum development and infection strategies noted on wheat (Bushnell et al. 2003; Kang and Buchenauer 2000b; Pritsch et al. 2000) are largely conserved during barley infection. Similar to the disease progression on wheat, $F$. graminearum infection of barley floral structures likely proceeds through direct penetration of cells via the infection-peg-like and coralloid structures, through stomatal pores, and by growing from the abaxial to the adaxial side of floral bracts. However, we have observed casually that the timing of infection on barley compared with wheat is different. Infection structure development and other morphological changes were observed between 12 and $24 \mathrm{~h}$ earlier in wheat than in barley. For example, germination of the fungal spores on wheat occurred within 6 hai (Pritsch et al. 2000); whereas, in barley, we did not observe germination until 24 hai. Coincident with the later symptom development in barley, the development of $F$. graminearum infection structures is delayed. This delay could be due to physiological differences in barley flowers compared with wheat or different morphological or anatomical differences in barley and wheat flowers. The delayed germination of fungal structures also could provide barley with a window of time to respond to infection and restrict spread of the disease.

\section{Transcript accumulation patterns \\ in barley during $\boldsymbol{F}$. graminearum infection.}

We identified two groups of gene expression patterns during $F$. graminearum infection. A qualitative group exhibited transcript accumulation patterns that were detected only upon inoculation, and a quantitative group exhibited greater transcript accumulation in inoculated compared with uninoculated (waterinoculated) plants. In all, 212 qualitative and 255 quantitative barley transcripts were identified. These data show that approximately one-half of all the barley genes that are induced are already making transcript (quantitative class) and possibly provide a basal level of defense. The other one-half of the genes are induced from undetectable (qualitative class) and are responding specifically to pathogen infection. Combined, these results demonstrate that barley mounts a substantial response to F. graminearum infection. Whether the quantitative transcript class plays a role in protecting barley from a variety of pathogens and, thus, exhibits a basal defense is unknown. Taken together, our data indicate that barley attempts to protect itself from pathogens by using a combination of basal and responsive defenses.

We identified only three genes that were downregulated during $F$. graminearum infection. The low number of downregulated genes likely is due to the methodology of $F$. graminearum inoculation we conducted. We spray inoculated the spikes and sampled the entire spike. Approximately $45 \%$ of the florets became diseased in our spray-inoculated experiments. We speculate that the lack of disease symptoms throughout the 
spike provided a set of transcripts that would always be derived from healthy tissue. To overcome this limitation and identify more downregulated transcripts, point inoculation and sampling of individual florets are required.

\section{Barley exhibits multiple responses}

to infection by $F$. graminearum.

Plants exhibit a variety of resistance mechanisms when attacked by a pathogen. The common generalized downstream responses include activation of defense response genes, oxidative burst, programmed cell death, phenylpropanoid pathway induction, and walling off of the pathogen (Apel and Hirt 2004; Birch et al, 1999; Hammond-Kosack and Jones 1996; Heath 2000; Kawasaki et al. 1999; Shirley 2001). In our Barley1 GeneChip experiments, we identified six functional classes of barley genes encoding defense response; metabolic, regulatory, and transporter proteins; and enzymes with miscellaneous and unknown functions. Within these functional

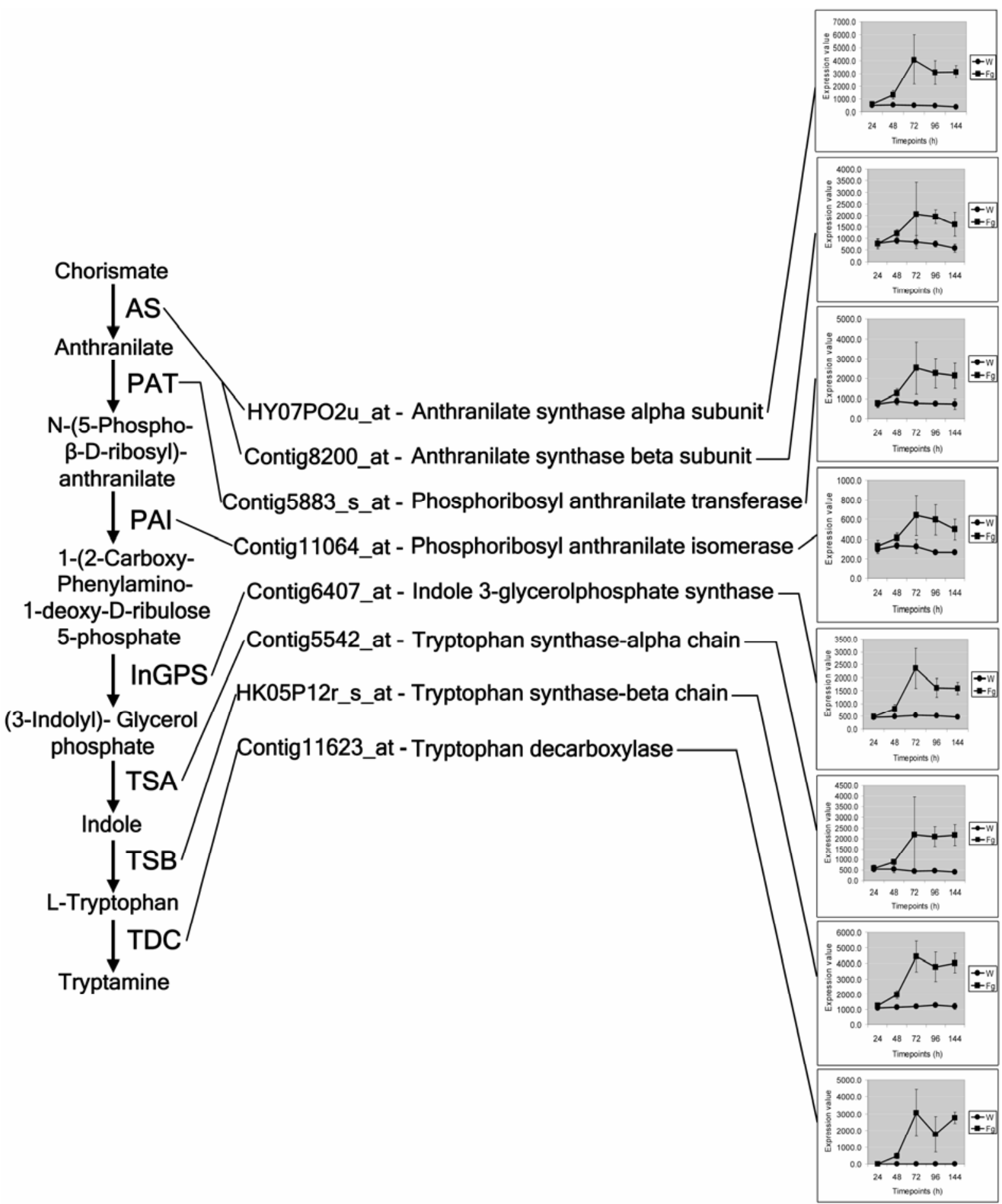

Fig. 4. Transcript accumulation in tryptophan biosynthetic and catabolic pathway genes during Fusarium graminearum infection of barley. Tryptophan biosynthetic and catabolic pathway. Abbreviated enzyme names are: AS, anthranilate synthase; PAT, phosphoribosyl anthranilate transferase; PAI, phosphoribosyl anthranilate isomerase; InGPS, indole 3-glycerol phosphate synthase; TSA, tryptophan synthase-alpha subunit; TSB, tryptophan synthase-beta subunit; TDC, tryptophan decarboxylase. Affymetrix IDs, corresponding annotations, and graphs show the transcript accumulation pattern of the selected transcripts across the tested time points. $\mathrm{W}=$ water-treated sample and $\mathrm{Fg}=$ F. graminearum-treated sample. 
classes, we identified genes that would fit into many of the generalized host responses to pathogen infection.

During $F$. graminearum infection of wheat, a set of defense response genes in the form of pathogenesis-related (PR) genes and oxidative burst-related genes such as peroxidase are activated locally and systemically (Kang et al. 2003; Li et al. 2001; Pritsch et al. 2000, 2001). Increased constitutive production of PR proteins encoded by chitinase and $\beta$-1,3-glucanase genes were correlated with resistance in wheat (Kang et al. 2003). In addition, overexpression of a gene encoding a rice thaumatinlike protein 1 in transgenic wheat resulted in delayed onset of FHB (Chen et al. 1999), although these same plants grown in the field did not exhibit FHB resistance (Anand et al. 2003). Moreover, involvement of peroxidase in resistance of wheat to $F$. graminearum recently has been reported (Mohammadi and Kazemi 2002). Thus, in wheat, there appears to be a substantial induction of defense response and oxidative burst-type genes, and the function of these genes is loosely correlated with FHB resistance. Our Barley1 GeneChip analysis showed induction of transcripts encoded by PR genes and oxidative burst-type genes such as glutathione $S$-transferases, peroxidases, and oxalate oxidase. Moreover, regulatory genes such as WRKY-class transcription factors were identified. WRKY transcription factors previously have been shown to interact with PR genes in the parsley-Phytophthora sojae interaction (Eulgem et al. 2000; Maeo et al. 2001). Therefore, these genes may induce the PR genes in barley during $F$. graminearum infection. Taken together, our results show the timing and level of transcript accumulation for a wide variety of PR and oxidative burst-related genes, indicating that barley responds to $F$. graminearum infection in a fashion similar to wheat. Whether the expression of these genes provides protection to barley during $F$. graminearum infection is unknown.

The induction of genes involved in the phenylpropanoid biosynthetic pathway is well documented in plant-pathogen interactions (Dixon and Steele 1999; Nicholson and Hammerschmidt 1992). Phenylpropanoid metabolites are utilized for biosynthesis of a variety of cellular compounds and structures, such as anthocyanins, lignin, and phytoalexins (Dixon 2001). However, induction of the phenylpropanoid pathway in the small grain- $F$. graminearum interactions has not been reported. We identified eight transcripts encoding phenylpropanoid pathway enzymes that were induced during Fusarium spp. infection. Increased lig- nin production has been identified at the sites of $F$. culmorum infection of resistant wheat genotypes (Kang and Buchenauer 2000c). In addition, the accumulation of the anthocyanin dihydroquercetin in the barley ant-18-159 mutant results in enhanced resistance to $F$. graminearum infection (Skadhauge et al. 1997). Whether the upregulation of the phenylpropanoid pathway results in increased lignin production, phytoalexins, and the synthesis of antifungal anthocyanins during $F$. graminearum infection of barley is unknown. However, our results showing that the phenylpropanoid pathway is induced during the barley- $F$. graminearum interaction suggests that phenylpropane derivatives play a role in the defense response.

Biosynthesis of trichothecenes is related to $F$. graminearum virulence because their accumulation inhibits host protein synthesis (McLaughlin et al. 1977) and other cellular effects, such as inhibition of mitochondrial enzymes and electrolyte loss (Cosette and Miller 1995). F. graminearum loss-of-function mutations in the Tri5 gene, encoding the first enzyme in the trichothecene pathway, result in the inability to synthesize trichothecenes and reduced virulence on wheat (Proctor et al. 1995). In addition, the Arabidopsis UDP-glucosyltransferase was recently found to detoxify trichothecenes synthesized by infecting Fusarium (Poppenberger et al. 2003). Thus, we searched for genes that may have a role in detoxifying or transporting trichothecenes in barley. Nine probe sets of UDP-glucosyltransferases were identified. The identification of UDP-glucosyltransferases indicates that barley responds to trichothecene production by inducing a set of genes that have the potential to alter the structure of trichothecenes. Genes that potentially encode transporter proteins that transport trichothecenes out of the cell or into the vacuole also were examined. We identified 12 probe sets annotated as $\mathrm{ABC}$ transporters and 2 probe sets showing high similarity to multidrug and toxic compound extrusion (MATE) factors in our analysis. These types of transporters have been shown to shuttle toxic compounds out of the cell or transport glutathione-S-conjugates into the vacuole (Jasinski et al. 2003; Sanchez-Fernandez et al. 2001). Defense response induction of ABC transporters (Campbell et al. 2003), their significance in conferring resistance to antifungal compound sclareol (van den Brule et al. 2002), and the importance of MATE family proteins in disease resistance (Nawrath et al. 2002) recently have been reported. Thus, in the barley- $F$. graminearum interaction, one possible function of these transporters is to shuttle trichothe-

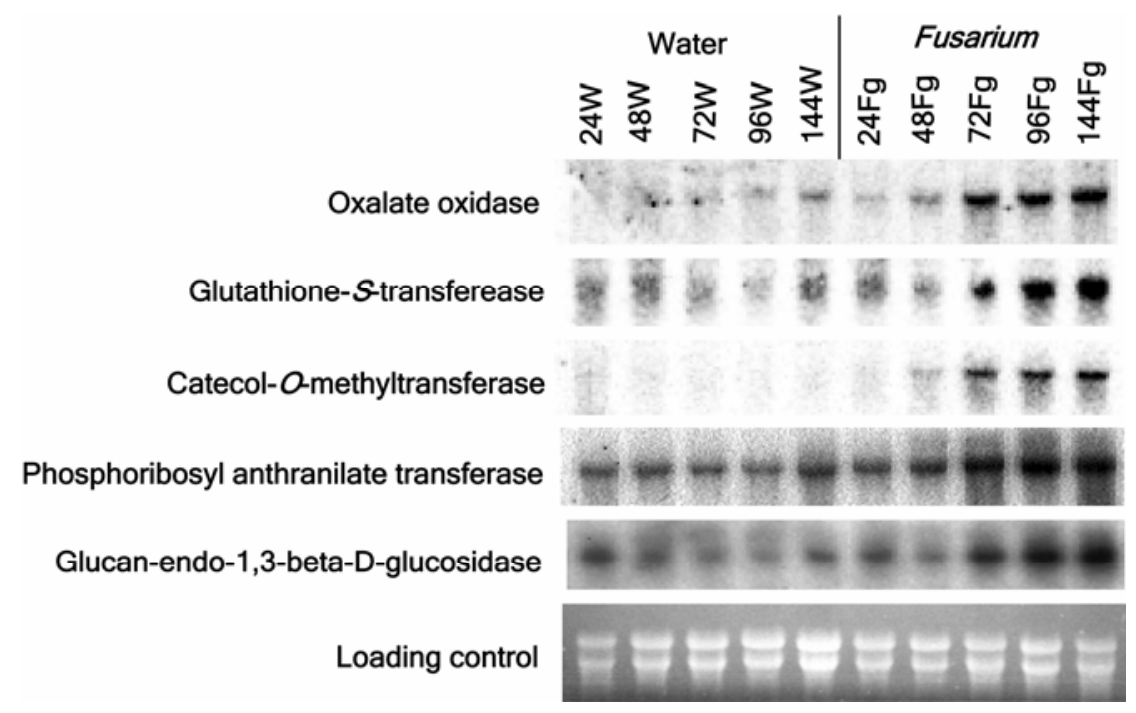

Fig. 5. RNA-gel blot validation of GeneChip data. Probes used for the hybridizations are shown to the left of the autoradiographs. $24 \mathrm{~W}$ and $24 \mathrm{Fg}$ represent RNA isolated from spikes $24 \mathrm{~h}$ after treatment with water or $F$. graminearum, respectively; with the other time points and treatments labeled in a similar fashion. The last panel shows ethidium bromide-stained loading controls exhibiting approximately equal loading of RNA. 
cenes into the vacuole or out of the cell to reduce the concentration of these compounds in the cytoplasm.

The tryptophan biosynthetic and catabolic pathways are induced.

Amino acids, especially aromatic amino acids, act as precursors for a wide variety of secondary metabolites that influence various defense responses (Conn 1995; Kutchan 1995). We found gene transcripts encoding biosynthetic and catabolic enzymes in the tryptophan metabolic pathway upregulated in barley infected with $F$. graminearum. We also identified an upregulated shikimate kinase gene transcript in the shikimate pathway, a pathway that supplies precursors to the tryptophan biosynthetic pathway. Transcript accumulation of the tryptophan biosynthetic genes was classified as quantitative in nature, suggesting a basal requirement for the essential amino acid tryptophan and for various metabolic activities in the plant. The upregulation of the tryptophan biosynthetic pathway in the infected plants shows its added involvement in defense response. Interestingly, the transcript encoding the tryptophan decarboxylase enzyme (TDC), converting tryptophan to tryptamine in the catabolism of tryptophan, exhibited a qualitative accumulation pattern, indicating that tryptamine or its indole derivatives are specifically increased and may be involved in protecting the plant during infection.

A variety of plant-pathogen interactions and abiotic stresses induce genes encoding tryptophan biosynthetic and catabolic enzymes. Wheat ESTs annotated as tryptophan decarboxylase were identified that specifically were expressed in plant-pathogen interactions (Kruger et al. 2002). Transcripts encoding phosphoribosyl anthranilate transferase, as well as other tryptophan biosynthetic enzymes, are induced more than fivefold in Arabidopsis within 1 day of inoculation with Pseudomonas syringe pv. maculicola (Zhao and Last 1996). Transcripts encoding anthranilate synthase also are upregulated by stress and fungal elicitors (Niyogi and Fink 1992). Induction of the tryptophan biosynthetic pathway in Arabidopsis during a variety of stress

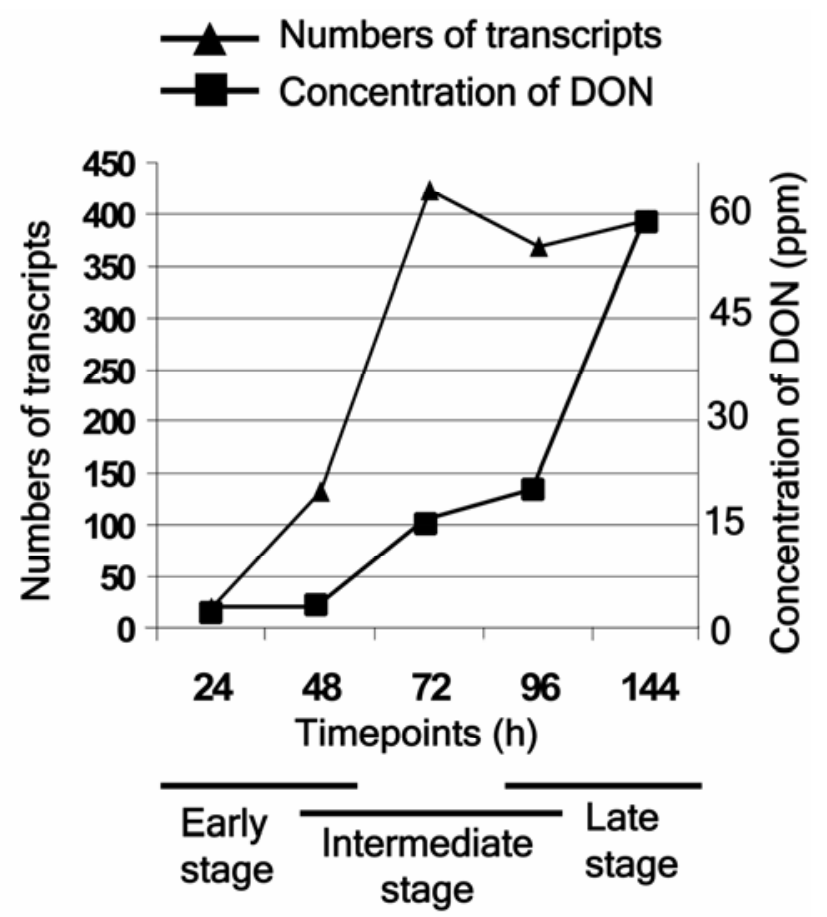

Fig. 6. Model showing the relationships among the number of host transcripts detected, deoxynivalenol (DON) concentration, and stages of infection during the barley-Fusarium graminearum interaction. conditions was observed (Zhao et al. 1998), suggesting that indole derivatives might be involved in stress tolerance in plants. Indeed, induced resistance by indolic compounds such as indole-3-acetic acid (IAA), tryptamine, and tryptophan in barley to Magnaporthe grisea also was observed (Ueno et al. 2004). The upregulation of transcripts encoding shikimate and tryptophan biosynthetic pathway enzymes also has been shown in the barley-B. graminis sp. f. hordei interaction (Caldo et al. 2004). These authors examined compatible and incompatible interactions of gene-for-gene barley-powdery mildew interactions and showed the induction of these genes in barley infected with $B$. graminis f. sp. hordei and the association of increased transcript accumulation with the incompatible interaction. Thus, our results are consistent with previous reports and extend the observations showing that aromatic amino acids and indole derivatives are essential components of host pathogen response.

\section{The Barley1 GeneChip}

can detect $F$. graminearum transcript accumulation.

The presence of probe sets that detect transcripts derived from $F$. graminearum genes provide the opportunity to detect fungal transcript accumulation during infection and determine the timing of gene expression in $F$. graminearum. Interestingly, the majority of the transcripts initially were detected at 72 hai, coincident with the timing of the generalized host response. The detection of the majority of $F$. graminearum transcripts at 72 hai likely is due to the increase of in planta fungal mass as shown in the histological observations and, thus, increased mRNA mass. The combined histological observations, DON accumulation data, and transcript accumulation data clearly indicate that the 72-hai timepoint is important for the continued development of Fusarium spp. during barley infection.

\section{Three stages of $F$. graminearum infection on barley.}

Transcript accumulation patterns, level of DON accumulation, and microscopic analysis suggest that there are three stages of the barley-F. graminearum interaction (Fig. 6). During the first stage, between 0 and 48 hai, there is little DON accumulation, the pathogen does not appear to penetrate cell walls, and just a small proportion of the host transcripts are induced. During this period, the pathogen behaves like a biotroph (Bushnell et al. 2003) and the host has just begun to recognize that it is under attack. In the intermediate stage, between 48 and 96 hai, the pathogen initiates trichothecene biosynthesis and switches to a necrotrophic mode of infection (Bushnell et al. 2003). At this time, the host fully recognizes infection has occurred and responds with a variety of defense strategies. By 72 hai, transcripts for most of the host genes responding to infection are detected. Thus, between 48 and 72 hai, the host defense response has been activated. In the late stage, between 96 and 144 hai, the number of transcripts is reduced from the 72 hai timepoint, the level of DON increases 3.5-fold higher than during the proceeding intermediate stage, and necrosis is clearly visible. Thus, this late timing is associated with the necrotrophic stage of infection. Four gene expression patterns (Q15, QL6, Qn5, and Qn6) were specific to the 96 and 144 hai timepoints (Fig. 3). Therefore, these gene sets provide an avenue to examine the necrotrophic stage of disease development. Finally, the three stages of the F. graminearum interaction described here provide the framework for further studies on host and pathogen genes that are expressed at particular stages in the development of the disease.

\section{Baseline dataset}

for small grains during $\boldsymbol{F}$. graminearum infection.

The transcript accumulation data generated from Morex barley infected with $F$. graminearum are publicly available on the BarleyBase website (Shen et al. 2005) for a variety of com- 
parative studies and hypothesis generation. The data are MIAME compliant and derived from the industry standard malting quality barley cultivar during infection by an important pathogen. The recent development of Affymetrix GeneChips for related grasses such as wheat, rice, and maize will provide a standard platform for comparative studies. Thus, our data will be useful for a variety of studies examining transcript profiles, including barley during infection by mutants of $F$. graminearum, wheat during $F$. graminearum infection, wheat and barley during infection with a variety of pathogens, and other plants during pathogen infection.

\section{MATERIALS AND METHODS}

\section{Plant and fungal material, inoculations, and sampling.}

The FHB-susceptible barley cv. Morex was used throughout this study. The monosporic isolate of Butte 86 (supplied by R. Dill-Macky, University of Minnesota) was used for all the inoculations.

Barley seed were planted in Scotts MetroMix 200 in 6-inch pots (four seeds per pot) and plants were grown in a growth chamber with a $16-\mathrm{h}$ day at $20^{\circ} \mathrm{C}$ and 8 -h night at $18^{\circ} \mathrm{C}$. The light intensity at pot level was $170 \pm 20 \mu \mathrm{E} \mathrm{m} \mathrm{m}^{-2} \mathrm{~s}^{-1}$. After a week, $5 \mathrm{ml}$ of Osmocote 14/14/14 (Marysville, OH, U.S.A.) with micronutrients was applied. Plants were watered every 2 to 3 days until 14 days and then every day until sampling.

Spikes were spray inoculated 2 to 3 days after emerging from the boot (plant ontology: 7.03-anthesis completed GRO:0007104) with a freshly prepared spore suspension of 2 $\times 10^{6}$ macroconidia $/ \mathrm{ml}$ in $0.04 \%$ ( $\mathrm{vol} / \mathrm{vol}$ ) Tween 20 in water or with water plus Tween 20 (mock). Spray inoculations were performed with an airbrush (Model VL; Paasche Airbrush, Harwood Heights, IL, U.S.A.) adjusted to a pressure of 82.8 $\mathrm{kPa}$ at $3 \mathrm{pm}$. After inoculation, the spikes were bagged in clear plastic for up to $72 \mathrm{~h}$.

\section{Experimental design.}

Four biological replicates of the experiment were conducted at $24,48,72,96$, and 144 hai with $F$. graminearum and a mock water control. A fifth replication was conducted for the 24 and 72 hai timepoints. Eight spikes were sampled at 24, 48, 72, 96, and 144 hai, flash frozen in liquid nitrogen, and stored at $-80^{\circ} \mathrm{C}$. Spikes were sampled at $3 \mathrm{pm}$ on each of the sampling days. Three to five infected plants in each replication were scored for disease severity (number of diseased florets/number of total florets) at 10 days after inoculation.

\section{Barley1 Affymetrix GeneChip probe array.}

The Barley1 GeneChip probe array (Affymetrix, Santa Clara, CA, U.S.A.) consisted of 22,792 probe sets (Close et al. 2004) corresponding to 22,439 barley genes. Exemplar sequences for the GeneChip design were derived from approximately 350,000 barley ESTs. Probe sets consisted of pairs of 11 matched and 11 mismatched 25-mer oligonucleotides designed primarily from the $3^{\prime}$ end of each exemplar sequence. We assumed that each probe set was equivalent to a transcript. Nucleotide number 13 is the location for the mismatched nucleotide.

\section{RNA extraction and processing, and Barley1 GeneChip hybridization, washes, and data acquisition.}

Spikes from each replication, treatment, and timepoint were pooled and ground in liquid nitrogen. Total RNA was extracted from $1 \mathrm{~g}$ of tissue using the Trizol (Invitrogen, Carlsbad, CA, U.S.A.) protocol. Genomic DNA was digested using RNasefree DNase and the RNA was purified on RNeasy columns (Promega Corp., Madison, WI, U.S.A.).
Prior to labeling, total RNA quality was examined on an Agilent 2100 bioanalyzer (Agilent, Palo Alto, CA, U.S.A.). cDNA synthesis was conducted with $15 \mu \mathrm{g}$ of total RNA and T7-Oligo(dT) primer (Proligo, Boulder, CO, U.S.A.) using the SuperScript Double-Stranded cDNA Synthesis Kit (Invitrogen). The cDNA was purified with the Affymetrix GeneChip sample cleanup module (Affymetrix, Santa Clara, CA, U.S.A.). To produce biotinylated cRNA, the cDNA was transcribed in vitro using the Enzo BioArray HighYield RNA transcript labeling kit (Enzo Life Sciences, Farmingdale, NY, U.S.A.) in the presence of biotinylated UTP and CTP. The biotin-labeled cRNA was purified with the Affymetrix GeneChip Sample Cleanup Module (Affymetrix). Labeled RNA $(15 \mu \mathrm{g})$ was chemically fragmented using the Affymetrix GeneChip sample cleanup module (Affymetrix) and used for hybridization. The chip hybridizations, washes, and chip reading were conducted in the Biomedical Image Processing Facility at the University of Minnesota following standard Affymetrix procedures.

\section{GeneChip data analysis.}

GeneChip data were obtained from Morex spikes 24, 48, 72, 96 , and $144 \mathrm{~h}$ after $F$. graminearum and mock water inoculation. Data analysis was conducted using Genedata Expressionist Pro software version 1.0 (Genedata, San Francisco, U.S.A.), which has two major tools: Refiner for condensation and normalization and Analyst for analysis of the data. The data were condensed and normalized through the Refiner tool. Within Refiner, we chose the RMA (Irizarry et al. 2003) algorithm for the condensation and normalization. The RMA-normalized signal was rescaled at a target intensity of 500. Correlation coefficients were calculated on the normalized data between replications and they ranged from 0.89 to 0.99 . A parametric two-way ANOVA $(P$ value $\leq 0.001)$ test, with an assumption of equal variance, was conducted on log-transformed data with a detection quality of 1 to identify differentially expressed genes by treatment effect (Fusarium infection or water control), time effect, and the treatment-time interaction. A detection quality of 1 provided a value for each transcript regardless of the level of the signal. FDR (Benjamini and Hochberg 1995) at 5\% was applied as a multiple test correction. At this stage, we conducted a presence or absence test for transcripts exhibiting differential accumulation using the MAS 5.0 algorithm $(P$ value $=0.04)$ in the Analyst tool. Transcripts showing differential accumulation, mainly due to the time effect without association with treatment effect, were excluded from further analysis. Differential expression patterns were classified as either qualitative or quantitative depending on transcript detection patterns (present or absent) or transcript abundance differences, respectively. Transcripts showing qualitative differential expression were detected in at least two replications in a given treatment, and not detected in any replications in the other treatment. Transcripts showing quantitative differential expression were detected based on a twofold difference between treatments. We manually clustered all qualitative and quantitative transcripts based on their time-dependent expression patterns. All GeneChip data in the form of CEL, DAT, CHP and TXT were deposited in the BarleyBase database. The accession number for the experiment is BB9.

We classified the differentially expressing genes into seven functional classes based on the annotation of the probe sets at HarvEST. These seven functional classes included genes encoding defense response, metabolic enzymes, regulatory proteins, fungal proteins, transporter proteins, miscellaneous proteins, and proteins of unknown function. Genes were classified as fungal by conducting BLASTN searches against the $F$. graminearum genome sequence at the Fusarium graminearum database. F. 
graminearum annotations were obtained from the Munich Information Center for Protein Sequences database. Genes were placed in the $F$. graminearum class if the $e$ value was $\leq 10^{-84}$ and percent nucleotide identity was $\geq 95 \%$ for the comparisons to the $F$. graminearum genome sequence. Barley genes were placed into a functional class if the $e$ value was $\leq 10^{-10}$; otherwise, they were placed in the unknown class.

\section{RNA gel blot analysis.}

Total RNA (10 $\mu \mathrm{g})$ was electrophoresed on $1.2 \%$ formaldehyde-agarose gels and transferred to Hybond-N+ membranes (Amersham Pharmacia Biotech, Piscataway, NJ, U.S.A.). DNA probes were labeled with ${ }^{32}$ P-dATP using Prime-a-Gene labeling system following the manufacturer's instructions (Promega Corp.) and purified using OrobeQuant G-50 Micro Columns (Amersham Biosciences). Prehybridizations and hybridizations were carried out using the modified Church and Gilbert buffer (Church and Gilbert 1984) at $65^{\circ} \mathrm{C}$. Washes were conducted in $1 \times \mathrm{SSC}(1 \times \mathrm{SSC}$ is $0.15 \mathrm{M} \mathrm{NaCl}$ plus $0.015 \mathrm{M}$ sodium citrate) and $0.1 \%$ sodium dodecyl sulfate at $65^{\circ} \mathrm{C}$. Membranes were exposed to a Phosphor Screen for $24 \mathrm{~h}$ and scanned by a PhosphorImager (pixel size, 176 microns; volt, 650) (Molecular Dynamics, Inc., Sunnyvale, CA, U.S.A.).

\section{DNA probes.}

DNA probes for the RNA gel blot analysis were obtained from A. Kleinhofs at Washington State University. All probes were derived from a barley EST project (Close et al. 2001). Probe set designation, functional annotation, and GenBank numbers for each clone were Contig3017_at, oxalate oxidase, BI949639; Contig14387_at, glutathione- $S$-transferase, BE214864; Contig17361_at, catechol-O-methyltransferase, BI949226; Contig5883_s_at, phosphoribosyl anthranilate transferase, BE216145; and Contig1637_s_at, glucan-endo1,3- $\beta$-D-glucosidase, BI951839.

\section{Microscopy.}

Lemma tissue was obtained from $F$. graminearum or water spray-inoculated Morex spikes at 24, 48, 72, 96, and 144 hai. Tissue was stained in aniline blue $(0.05 \%$ in lactoglycerol). Aniline blue-stained fungal structures were observed under a Zeiss light microscope. Images were captured on a computer and observations recorded.

For scanning electron microscopy, lemma tissues were immersed in $50 \%$ glycerol for a minimum of $24 \mathrm{~h}$. The tissue was placed on the observation stub and the excess glycerol was removed carefully by blotting with a filter paper. The observations were taken and recorded at the Image Center facility of University of Minnesota using the Hitachi S3500N VPSEM Model electron microscope (Gaithersburg, MD, U.S.A.).

\section{Determination of DON concentration.}

For each replication-treatment-timepoint combination, the same spikes used for the RNA isolations were used for DON analysis. DON concentration was determined using gas chromatography and expressed as parts per million according to the procedures of Mirocha and associates (1998).

\section{ACKNOWLEDGMENTS}

This work was supported by grants to G. J. Muehlbauer from the United States Department of Agriculture Initiative for Future Agriculture and Food Systems grant 02-35300-12619 and the United States Wheat and Barley Scab Initiative. We would like to thank C. Vance and H. C. Kistler for critical review of the manuscript and R. Dill-Macky for the Butte $86 F$. graminearum isolate.

\section{LITERATURE CITED}

Anand, A., Zhou, T., Trick, H. N., Gill, B. S., Bockus, W. W., and Muthukrishnan, S. 2003. Greenhouse and field testing of transgenic wheat plants stably expressing genes for thaumatin-like protein, chitinase and glucanase against Fusarium graminearum. J. Exp. Bot. 54:1101-1111.

Anderson, J. A., Stack, R. W., Liu, S., Waldron, B. L., Fjeld, A. D., Coyne, C., Moreno-Sevilla, B., Fetch, J. M., Song, Q. J., Cregan, P. B., and Frohberg, R. C. 2001. DNA markers for Fusarium head blight resistance QTLs in two wheat populations. Theor. Appl. Genet. 102:1164-1168.

Apel, K., and Hirt, H. 2004. Reactive oxygen species: Metabolism, oxidative stress, and signal transduction. Annu. Rev. Plant Biol. 55:373-399.

Bai, G., Kolb, F. L., Shaner, G., and Domier, L. L. 1999. Amplified fragment length polymorphism markers linked to a major quantitative trait locus controlling scab resistance in wheat. Phytopathology 89:343-348.

Benjamini, Y., and Hochberg, Y. 1995. Controlling the false discovery rate: A practical and powerful approach to multiple testing. J. R. Stat. Soc. B. 57:289-300.

Birch, P. R. J., Avrova, A, O., Duncan, J. M., Lyon, G. D., and Toth, R. L. 1999. Isolation of potato genes that are induced during an early stage of the hypersensitive response of Phytophthora infestans. Mol. PlantMicrobe Interact. 12:356-361.

Buerstmayr, H., Lemmens, M., Hartl, L., Doldi, L., Steiner, B., Stierschneider, M., and Ruckenbauer, P. 2002. Molecular mapping of QTLs for Fusarium head blight resistance in spring wheat. I. Resistance to fungal spread (type II resistance). Theor. Appl. Genet. 104:84-91.

Bushnell, W. R., Hazen, B. E., and Pritsch, C. 2003. Histology and physiology of Fusarium head blight. Pages 44-83 in: Fusarium Head Blight of Wheat and Barley. K. J. Leonard and W. R. Bushnell, eds. American Phytopathological Society Press, St. Paul, MN, U.S.A.

Caldo, R. A., Nettleton, D., and Wise R. P. 2004. Interaction-dependent gene expression in Mla-specified response to barley powdery mildew. Plant Cell 16:2514-2528.

Campbell, E. J., Schenk, P. M., Kazan, K., Penninckx, I. A. M. A., Anderson, J. P., Maclean. D. J., Cammue, B. P. A., Ebert, P. R., and Manners, J. M. 2003. Pathogen-responsive expression of a putative ATP-binding cassette transporter gene conferring resistance to the diterpenoid sclareol is regulated by multiple defense signaling pathways in Arabidopsis. Plant Physiol. 133:1272-1284.

Chen, W. P., Chen, P. D., Liu, D. J., Kynast, R., Friebe, B., Velazhahan, R., Muthukrishnan, S., and Gill, B. S. 1999. Development of wheat scab symptoms is delayed in transgenic wheat plants that constitutively express a rice thaumatin-like protein gene. Theor. Appl. Genet. 99:755-760.

Church, G. M., and Gilbert, W. 1984. Genomic sequencing. Proc. Natl. Acad. Sci. U.S.A. 81:1991-1995.

Close, T. J., Wing, R., Kleinhofs, A., and Wise, R. P. 2001. Genetically and physically anchored EST resources for barley genomics. Barley Genet. Newsl. 31:29-30.

Close, T. J., Wanamaker, S. I., Caldo, R. A., Turner, S. M., Ashlock, D. A., Dickerson, J. A., Wing, R. A., Muehlbauer, G. J., Kleinhofs, A., and Wise, R. P. 2004. A new resource for cereal genomics: 22K Barley GeneChip comes of age. Plant Physiol. 134:960-968.

Conn, E. E. 1995. The world of phytochemicals. Pages 1-14 in: Phytochemicals and Health, Vol. 15. D. L. Gustine and H. E. Flores, eds. American Society of Plant Physiologists, Rockville, MD, U.S.A.

Cosette, F., and Miller, J. D. 1995. Phytotoxic effect of deoxynivalenol and Gibberella ear rot resistance of corn. Nat. Toxins 3:383-388.

Dahleen, L. S., Agrama, H. A., Horsley, R. D., Steffenson, B. J., Schwarz, P. B., Mesfin, A., and Franckowiak, J. D. 2003. Identification of QTLs associated with Fusarium head blight resistance in Zhedar 2 barley. Theor. Appl. Genet. 108:95-104.

de la Peña, R., Smith, R. C., Capettini, F., Muehlbauer, G. J., Gallo-Meagher, M., Dill-Mackey, R., Somers, D. A., and Rasmusson, D. C. 1999. Quantitative trait loci associated with resistance to Fusarium head blight and kernel discoloration in barley. Theor. Appl. Genet. 99:561-569.

Desjardins, A. E., and Hohn, T. M. 1997. Mycotoxins in plant pathogenesis. Mol. Plant-Microbe Interact. 10:147-152.

Dixon, R. A. 2001. Natural products and plant disease resistance. Nature 411:843-847.

Dixon, R. A., and Steele, C. L. 1999. Flavonoids and isoflavonoids-A gold mine for metabolic engineering. Trends Plant Sci. 4:394-400.

Eulgem, T., Rushton, P. J., Robatzek, S., and Somssich, I. E. 2000. The WRKY superfamily of plant transcription factors. Trends Plant Sci. 5:199-206.

Hammond-Kosack, K. E., and Jones, J. D. G. 1996. Resistance gene-dependent plant defense responses. Plant Cell 8:1773-1791.

Heath, M. C. 2000. Non-host resistance and nonspecific plant defenses. Curr. Opin. Plant Biol. 3:315-319.

Irizarry, R. A., Hobbs, B., Collin, F., Beazer-Barclay, Y. D., Antonellis, K. 
J., Scherf, U., and Speed, T. P. 2003. Exploration, normalization, and summaries of high density oligonucleotide array probe level data. Biostatistics 4:249-264.

Jasinski, M., Ducos, E., Martinoia, E., and Boutry, M. 2003. The ATPbinding cassette transporters: Structure, function, and gene family comparison between rice and Arabidopsis Plant Physiol. 131:1169-1177.

Kang, Z., and Buchenauer, H. 1999. Immunocytochemical localization of Fusarium toxins in infected wheat spikes by Fusarium culmorum. Physiol. Mol. Plant. Pathol. 55:275-288.

Kang, Z., and Buchenauer, H. 2000a. Cytology and ultrastructure of the infection of wheat spikes by Fusarium culmorum. Mycol. Res. 104:1083-1093.

Kang, Z., and Buchenauer, H. 2000b. Ultrastructural and cytochemical studies on cellulose, xylan and pectin degradation in wheat spikes infected by Fusarium graminearum. J. Phytopathol. 148:263-275.

Kang, Z., and Buchenauer, H. 2000c. Ultrastructural and immunocytochemical investigation of pathogen development and host responses in resistant and susceptible wheat spikes infected with Fusarium culmorum. Physiol. Mol. Plant Pathol. 57:255-268.

Kang, Z., and Buchenauer, H. 2002. Immunocytochemical localization of $\beta$-1,3-glucanase and chitinase in Fusarium culmorum-infected wheat spikes. Physiol. Mol. Plant Pathol. 60:141-153.

Kang, Z., Huang, L. L., and Buchenauer, H. 2003. Subcellular localization of chitinase and $\beta$-1,3-glucanase in compatible and incompatible interactions between wheat and Puccinia striiformis f. sp tritici. Z. Pflanzenkrankh. Pflanzenschutz, J. Plant Dis. Prot. 110:170-183.

Kawasaki, T., Henmi, K., Ono, E., Hatakeyama, S., Iwano, M., Satoh, H. and Shimomoto, K. 1999. The small GTP-binding protein Rac is a regulator of cell death in plants. Proc. Natl. Acad. Sci. U.S.A. 96:10922-10926.

Kruger, W. M., Pritsch, C., Chao, S., and Muehlbauer, G. J. 2002. Functional and comparative bioinformatics analysis of expressed genes from wheat spikes infected with Fusarium graminearum. Mol. PlantMicrobe Interact. 15:445-455.

Kutchan, T. M. 1995. Alkaloid biosynthesis-the basis for metabolic engineering of medicinal plants. Plant Cell 7:1059-1070.

Li, W. L., Faris, J. D., Muthukrishnan, S., Liu, D. J., Chen, P. D., and Gill, B. S. 2001. Isolation and characterization of novel cDNA clones of acidic chitinases and $\beta$-1,3-glucanases from wheat spikes infected by Fusarium graminearum. Theor. Appl. Genet. 102:353-362.

Ma, Z., Steffenson, B. J., Prom, L. K., and Lapitan, N. L. V. 2000. Mapping of quantitative trait loci for Fusarium head blight in barley. Phytopathology 90:1079-1088.

Maeo, K., Hayashi, S., Kojima-Suzuki, H., Morikami, A., and Nakamura, D. 2001. Role of conserved residues of the WRKY domain in the DNAbinding of tobacco WRKY family proteins. Biosci. Biotechnol. Biochem. 65:2428-2436.

McLaughlin, C. S., Vaughn, M. H., Campbell, J. M., Wei, C. M., Stafford, M. E., and Hansin, B. S. 1977. Inhibition of protein synthesis by trichothecenes. Pages 263-273 in: Mycotoxins in Human and Animal Health. H. V. Rodricks, C. W. Hesseltine, and M. A. Mehlman, eds. Pathotoxin Publishers, Park Forest South, IL, U.S.A.

McMullen, M., Jones, R., and Gallenberg, D. 1997. Scab of wheat and barley: A re-emerging disease of devastating impact. Plant Dis. 81:1340-1348.

Mesfin, A., Smith, K. P., Dill-Macky, R., Evans, C. K., Waugh, R., Gustus, C. D., and Muehlbauer, G. J. 2003. Quantitative trait loci for Fusarium head blight resistance in barley detected in a two-rowed by six-rowed population. Crop Sci. 43:307-318.

Mesterhazy, A. 1995. Types and components of resistance to Fusarium head blight of wheat. Plant Breed. 114:377-386.

Miller, J. D., and Ewen, M. A. 1997. Toxic effects of deoxynivalenol on ribosomes and tissues of the spring wheat cultivars Frontana and Casavant. Nat. Toxins 5:234-237.

Mirocha, C. J., Kolaczkowski, E., Xie, W., Yu, H., and Jelen, H. 1998. Analysis of deoxynivalenol and its derivatives (batch and single kernel) using gas chromatography/mass spectrometry. J. Agric. Food Chem. 46:1414-1418.

Mohammadi, M., and Kazemi, H. 2002. Changes in peroxidase and polyphenol oxidase activities in susceptible and resistant wheat heads inoculated with Fusarium graminearum and induced resistance. Plant Sci. 162:491-498.

Nawrath, C., Heck, S., Parinthawong, N., and Metraux, J. P. 2002. EDS5, an essential component of salicylic acid-dependent signaling for disease resistance in Arabidopsis, is a member of the MATE transporter family. Plant Cell 14:275-286.

Nicholson, R. L., and Hammerschmidt, R. 1992. Phenolic compounds and their role in disease resistance. Annu. Rev. Phytopathol. 30:369-389.

Niyogi, K. K., and Fink, G. R. 1992. Two anthranilate synthase genes in
Arabidopsis: Defense-related regulation of the tryptophan pathway. Plant Cell 4:721-733.

Otto, C. D., Kianian, S. F., Elias, E. M., Stack, R. W., and Joppa, L. R. 2002. Genetic dissection of a major Fusarium head blight QTL in tetraploid wheat. Plant Mol. Biol. 48:625-632.

Parry, D. W., Jenkinson, P., and McLeod, L. 1995. Fusarium ear blight (scab) in small grain cereals-a review. Plant Pathol. 44:207-238.

Poppenberger, B., Berthiller, F., Lucyshyn, D., Sieberer, T., Schuhmacher, R., Krska, R., Kuchler, K., Glössl, J., Luschnig, C., and Adam, G. 2003. Detoxification of the Fusarium mycotoxin deoxynivalenol by a UDPglucosyltransferase from Arabidopsis thaliana J. Biol. Chem. 278:47905-47914.

Pritsch, C., Muehlbauer, G. J., Bushnell, W. R., Somers, D. A., and Vance, C. P. 2000. Fungal development and induction of defense response genes during early infection of wheat spikes by Fusarium graminearum. Mol. Plant-Microbe Interact. 13:159-169.

Pritsch, C., Vance, C. P., Bushnell, W. R., Somers, D. A., Hohn, T. M., and Muehlbauer, G. J. 2001. Systemic expression of defense response genes in wheat spikes as a response to Fusarium graminearum infection. Physiol. Mol. Plant Pathol. 58:1-12.

Proctor, R. H., Hohn, T. M., and McCormick, S. P. .1995. Reduced virulence of Gibberella zeae caused by disruption of a trichothecene toxin biosynthetic gene. Mol. Plant-Microbe Interact. 8:593-601.

Sanchez-Fernandez, R., Davies, T. G., Coleman, J. O., and Rea, P. A. 2001. The Arabidopsis thaliana ABC protein superfamily: A complete inventory. J. Biol. Chem. 276:30231-30244.

Shen, L., Gong, J., Caldo, R. A., Nettleton, D., Cook, D., Wise, R. P., and Dickerson, J. A. 2005. BarleyBase-An expression profiling database for plant genomics. Nucleic Acids Res. 33 (Database issue):D614-D618.

Skadhauge, B., Thomsen, K. K., and von Wettstein, D. 1997. The role of barley testa layer and its flavonoid content in resistance to Fusarium infections. Hereditas 126:147-160.

Skadsen, R. W., and Hohn, T. M. 2004. Use of Fusarium graminearum transformed with $g f p$ to follow infection patterns in barley and Arabidopsis. Physiol. Mol. Plant Pathol. 64:45-53.

Shifrin, V. I., and Anderson, P. 1999. Trichothecene mycotoxins trigger a ribotoxic stress response that activates c-Jun $\mathrm{N}$-terminal kinase and p38 mitogen-activated protein kinase and induces apoptosis. J. Biol. Chem. 274:13985-13992.

Shirley, B. W. 2001. Flavonoid biosynthesis. A colorful model for genetics, biochemistry, cell biology, and biotechnology. Plant Physiol. 126:485493.

Ueno, M., Kihara, J., Honda, Y., and Arase, S. 2004. Indole-related compounds induce the resistance rice blast fungus, Magnaporthe grisea in barley. J. Phytopathol. 152:606-612.

van den Brûle, S., Müller, A., Fleming, A. J., and Smart, C. C. 2002. The $\mathrm{ABC}$ transporter SpTUR2 confers resistance to the antifungal diterpene sclareol. Plant J. 30:649-662.

Waldron, B. L., Moreno-Sevilla, B., Anderson, J. A., Stack, R. W., and Frohberg, R. C. 1999. RFLP mapping of QTL for Fusarium head blight resistance in wheat. Crop Sci. 39:805-811.

Zhao, J. and Last, R. L. 1996. Coordinate regulation of the tryptophan biosynthetic pathway and indolic phytoalexin accumulation in Arabidopsis. Plant Cell 8:2235-2244.

Zhao, J., Williams C. C., and Last R. L. 1998. Induction of Arabidopsis tryptophan pathway enzymes and camalexin by amino acid starvation, oxidative stress, and an abiotic elicitor. Plant Cell 10:359-370.

Zhou, W. C., Kolb, F. L., Bai, G. H., Shaner, G., and Domier, L. L. 2002. Genetic analysis of scab resistance QTL in wheat with microsatellite and AFLP markers. Genome 45:719-727.

Zhu, L., Gilchrist, L., Hayes, P., Kleinhofs, A., Kudrna, D., Liu, Z., Prom, L., Steffenson, B. J., Toojinda, T., and Vivar, H. 1999. Does function follow form? Principal QTLs for Fusarium head blight (FHB) resistance are coincident with QTLs for inflorescence traits and plant height in a double-haploid population of barley. Theor. Appl. Genet. 99:1221 1232 .

\section{AUTHOR-RECOMMENDED INTERNET RESOURCES}

University of California, Riverside HarvEST website: harvest.ucr.edu

Broad Institute's Fusarium graminearum database: www.broad.mit.edu/annotation/fungi/fusarium

United States Department of Agriculture's BarleyBase website: www.barleybase.org

University of Minnesota Biomedical Image Processing Lab Affymetrix procedures: www.bipl.ahc.umn.edu/affymetrix.html

Munich Information Center for Protein Sequences database: mips.gsf.de/genre/proj/fusarium/About/people.html 